\title{
An analysis on the Regional Tourism Industry Performance with the Application of Information
}

\author{
Huijuan JIN \\ Tourism and Air Service College, \\ Guizhou Minzu University \\ Guiyang, China \\ e-mail: 47853433@qq.com
}

\author{
Min WEI \\ School of Management, \\ Xiamen University \\ Xiamen, China \\ e-mail: Xiada2000@126.com
}

\begin{abstract}
From the perspective of the tourism industry to the economy, econometrics and statistics theory, a study on the regional tourism industry development mechanism and comprehensive performance evaluation related to information, enrich and supplement the tourism industry economic theory research. The research contents include: theory, definition of comprehensive performance of regional tourism industry related to information core connotation; resources of regional tourism industry verification paradox; demonstrates the development mechanism of regional tourism industry based on the cracking of the "resource curse", and then construct the evaluation index system. The methodology, combined evaluation model to explore the regional tourism industry performance and efficiency with information application; influencing factors empirical research will focus on solving the interactive relationship between the information under the condition of regional tourism economic benefits. Finally, the paper puts forward the strategy of regional tourism industry performance improvement with information.
\end{abstract}

Keywords-information technology; performance; data sharing

\section{INTRODUCTION}

In the past 30 years, with the deepening of reform and opening up and the acceleration of economic modernization, in addition to a few (such as the 2003 SARS), the total size of China's tourism industry showed a rapid growth of nearly two digits. During the period, almost all of the tourism revenue is increasing. Nowadays, our country has gradually developed into a big tourism country in the world by the big country of tourism resources. The world tourism organization has even predicted that China will become a world tourism power in advance of 5 years, by 2015 China will become the world's largest inbound tourist reception country and the world's fourth largest outbound tourist country. Numerous studies have concluded that the emergence of information technology shows a great impact on tourism enterprises, on the structure of the tourism industry and on the tourist demands as well, which has threatened the traditional tourism enterprises but brought new opportunities. Changes in the travel distribution system brought by information technology are the hot research fields. Substantial researches are concerned with the impact of e-Tourism and the changes of business model. In view of the impact of tourism development on economic performance, the study of the central coast of Priski in the west of Australia, pointed out that natural resources are an important factor in the development of natural environment dependent tourism. Denicol et al. (2008) through the investigation of the development of tourism economy in Italy, which is rich in tourism resources, it is found that the tourism economic development in the region has been in the middle and low grade. With the development of network core competence brought about by the dynamic effect of innovation, and its economic development has been significantly improved. Buhalis also believes that the IT industry through the promotion of tourism market transactions and more convenient communication between consumers and management organizations, and significantly improve the efficiency and effectiveness of tourism development. Lee pointed out that the development of air transport in recent years has played an important role in the development of regional tourism. Conclusion the comprehensive study, Zhang and Jensen (2012) from the tourism destination supply side perspective, points out that the supply side factors such as natural resources, technology and infrastructure to promote international tourism is an important aspect of the development of tourism industry. Other studies, Russell and Faulkner believe that entrepreneurship is a key factor in the development of tourism. Gross and Brown (2013) believe that a higher degree of participation and a sense of belonging is an important aspect of destination tourism economic development. Mayaka and Akama(2016) put forward the tourism development framework from the perspective of education promotion.

\section{LITERATURE REVIEWS}

According to the analysis of our experience, Zhong et al (2015) pay attention to China of Zhangjiajie national Forest Park as an example, study found that the government and the private sector in the development of tourism economy plays an important role; at the same time, the relationship between economic development and local and even greater regional economic development have become more and more . Lu Lin and Yu Fenglong (2014) believe that the main factors that cause the regional spatial difference of tourism economy in China are tourism resources endowment, infrastructure, location factors and industrial structure factors. Liang Yihua emphasized the influence of service 
economy on the development of tourism industry. Wang Yuming and $\mathrm{Lu}$ Shuai believes that the construction of tourism image is an important. Xu Honggang and Tian Meirong using complex system theory and system dynamics tool, analysis of the city tourism growth model. The results show that most of the city depends on the investment of infrastructure, mining city historical and cultural resources to promote the growth of positive feedback, but restricts the growth mechanism of these vulnerable to investment decline and resource capacity and difficult to sustain, cannot avoid into rapid development into a stable development, even landslide growth stagnation. They pointed out that only the successful construction and development of commercial networks, the development of urban tourism industry clusters and innovation mechanisms, the formation of path dependent growth model, in order to promote the sustainable growth of urban tourism. In the research of micro enterprise level, Wang Chenguang and Kong Lihua think that the higher the proportion of the largest shareholder, the higher the performance of tourism enterprises, but its nature will not have a significant impact on the performance of. There is no significant difference in the level of performance of the board of directors of different companies, but the separation of chairman and general manager of the two will have a positive impact on corporate performance. Managerial ownership is helpful to improve firm performance, but its compensation does not affect firm performance.

Divided by the variable resource regression coefficient under visible, with the tourism income distribution condition by low-end (low points) to high (high bit) changes, the effect gradually reduced, even in the tourism income of $95 \%$ sub sites, the effect is changed to negative. This is a significant changes to our enlightenment is, although the tourism resources is one of the most important aspects of tourism revenues, but here if the tourism income distribution changes from small to large conditions as reflecting the development of the tourism industry scale if the show in the early stages of the development of the tourism industry, the tourism www. lwxz8. com www. lunwenshop. com Beijing the industrial scale is not great, this is the development process of tourism resources in the tourism industry, the important factors embodied in scale economic performance; and with the further development of the tourism industry, its size may also increase gradually, when the effect of tourism resources has become relatively small; with the further growth the development of the tourism industry and the size of the impact of tourism resources and eventually become a Restriction factors. From the microcosmic perspective, tourism enterprises rely on natural resources monopoly, unique and can't be copied. To determine the characteristics of tourism resources is relatively stable in a certain period of time; and with the development of the time evolution of tourism resources and tourism resources, marginal revenue management diminishing effect will appear, which makes the tourism business performance the enterprise in a long period, showing a relatively stable or even decline in the situation. Obviously, China's tourism industry as a whole has now developed to a later stage. For example, Shanxi, Henan and Sichuan are rich in tourism resources, but the economic performance of the tourism industry is not very good. One very important aspect is that the regional tourism industry in the development process, emphasizing the influence or excessive reliance on tourism resources to the development of the tourism industry. With the diversification of people's tourism consumption behavior, the development of tourism has surpassed the stage of tourism resources dependence. Especially in the case of the experience economy has gradually become a new form of tourism economy, tourists pay more attention to personalized service and flexible choice.

\section{INFORMATION TECHNOLOGY}

According to the 2014 China Tourism Statistical Bulletin, Chinese inbound tourist arrivals 12849. 83 million in 2014; National Tourism Bureau data center data shows, from January to November 2015, inbound tourism 12210. 14 million passengers, an increase of $4.4 \%$, China's inbound tourism into the steady development and benefit promotion stage. With the rapid development of network, exchanging information and data is encouraged in tourism. Initially, the tourism information requested is not comprehensive, and the importance of resource sharing and scale effect hasnot been fully realized so that data-sharing is still not concerned enough. And different types of tourism service provider possess different data, which may block the effective exchange of information. Personnel's knowledge professional level: Personnel's knowledge professional level isused to measure how well personnel have mastered the knowledge. The value of personnel's knowledge professional level is based on personnel's achievements in a knowledge domain. Personnel'sachievements include the number and levels of personnel's achievements in a knowledge domain, andthe roles of personnel in the achievements. Fortunately, advanced in information technology has this problem resolved. After establishing a unified data exchange standard in tourism information, effective information can be exchanged between tourism service providers. The unified data exchange standard is achieved through XML technology. Nowadays, data-sharing is supported by information technology, andthe performance of tourism service providers is needed to be improved urgently (Figure 1). 


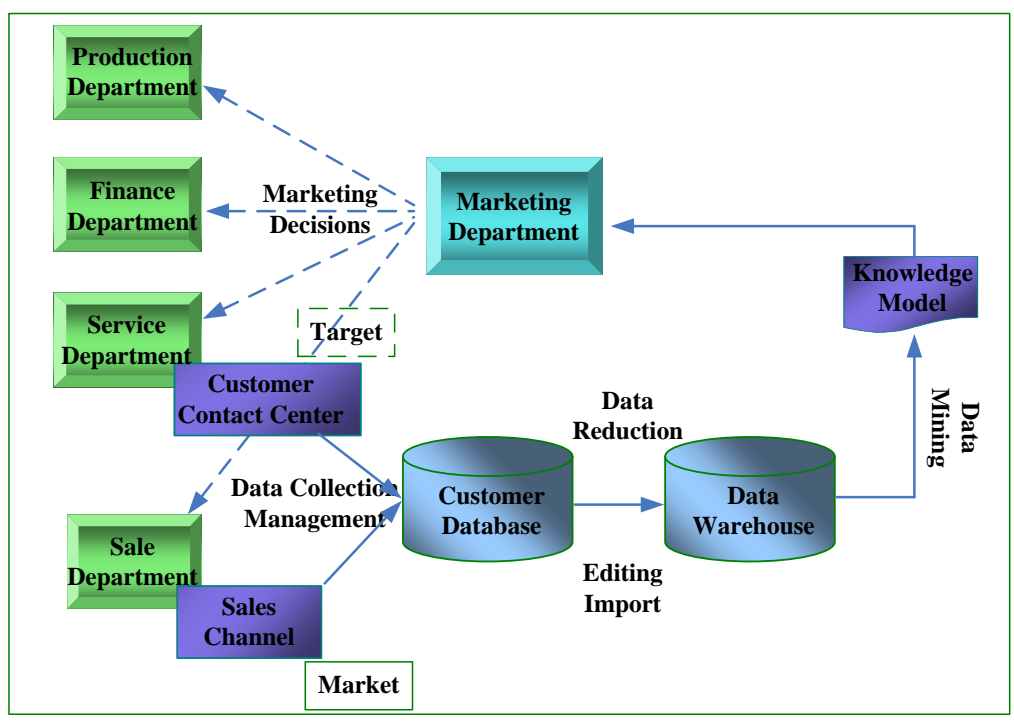

Figure 1. The general construction of data-sharing

Undoubtedly, internal management costs and transaction costs will be reduced if a proper way can be found to make fully use of data-sharing. With the cost advantage enterprises would like to expand production earning more profits, and the scale effect will in turn reduces cost further. In conclusion, taking advantage of data-sharing would enter a virtuous cycle.

Compared with ECP, the TP is completed through the actual contact offline, and it is helpful for the demander to absorb the new knowledge, that means the demander willacquire knowledge that have small distortion. So we could set the demander gets 1 as profitwhen they trade per unit of knowledge by TP. Because knowledge that traded by ECP iscoded, so that we can't define the distortion. Then we set the demander' profit would be $\left(\begin{array}{ll}0 & 1\end{array}\right)$, when they trade the same per unit of knowledge by ECP. Refers toknowledge's degree of explicitness, when the degree becomes higher, that means thedemander can absorb new knowledge more easily, then enterprises could get more profit. In the TP, the enterprises obey the reciprocal, so the supplier just lives on the return from receivers in the future without any other extra bonus; but in ECP, the supplierwould receive a disposable sum.

\section{INFORMATION AND TOURISM ENTERPRISES}

The difficulty to obtain comprehensive information on destinations created chances for the tourism intermediaries. Tourists mainly rely on travel intermediariesto obtain the information of tourism products before. While, with the advanced in information technology, information sources are more diverse than ever, which have an impact on the tourism supply chain. At present, the definition of tourism supply chain fails to reach an agreement. Here, tourism supply chain is defined as a network of tourism organizations engaged in different activities ranging from the supply of different components of tourism products/services such as flights and accommodation to the distribution and marketing of the final tourism product at a specific tourism destination, and involves a wide range of participants in both the private and public sectors(Xinyan Zhang, Haiyan Song, George Q. Huang, 2007). That is to say information technology has a deep impact on tourism service providers and their relationships. However, relationship between the tourism service providers is founded on the tourists' demand. This suggests that information technology has changed consumer demand and tourism business model.

Compared with the other three factors, the difference of labor is mostly positive, but it does not pass the significance test. Effect of human capital variables HR measured in different quantile conditions were significantly positive, from the point of view of the corresponding changes in the effects of the $5 \%$ sub sites is the biggest influence, with the tourism income scale quantile increasing, this effect decreased slightly, to $50 \%$ sites to the lowest, followed in $75 \%$ $95 \%$ sub sites, this effect has improved, the overall effect of showing a "U" change law. The material capital investment finally measured by the variable capital, in $5 \%$ to $50 \%$ points in the process of change, rising from $50 \%$ to $95 \%$, and showed a downward trend, namely the general regularity, its just different from the previous human capital under the influence law on the contrary, an inverted "U" type. Here further on the changes of human capital and material capital completely visible, if we put the development of the tourism industry as a series of investment activities around the tourism resources development. Then, in the early stage, the relative human capital, the development of tourism resources, the more need is a lot of material capital investment, therefore the marginal effect of physical capital investment is increasing, until the material capital investment to meet the basic needs of the development of tourism resources, the marginal effect will increase with further investment and gradual decline. Obviously, when the basic conditions for the development of tourism resources endowment have reached the requirements, the importance of human capital investment 
began to rise, and play an increasingly important role. Generally speaking, seen from here analysis of tourism resources, human capital and material capital to the tourism industry performance characteristics of the relative impact of changes is not difficult, the upgrading from primary to senior elements, the relative impact of changes in the importance and is gradually released.

Information technology revolution makes the competition environment changed. Traditional tourism service providers have to change the business structure to remain competitive. Large-scale traditional tourism enterpriseshave createdtheir own websites, such as CYTS, Spring Tour Network, while small and medium-sized tourism enterprises publish their information through a third party website likeSina, or Elong. In the purpose of expanding the market share, a combination of online and on-site business model is proposed. Compared to the traditional model, new model accelerates the flow of information, which brings convenience to potential tourists. In addition, the new structure will reduce the cost and improve the business performance at the same time. Nowadays, tourists hope that the related products can be more precise so that they can enjoy the holidays better. Explain in other words, cooperation between the tourism service providers should be gradually close, and the integration of industrial chain is on the way. Tourism enterprises began to provide diversified services. Apparently, the tourism enterprises will go to collectivization in the future. In the past, hotels, scenic spots and tourism intermediaries are cooperatingas independent corporates, and they would be more likely to work together as a union group. Hence, business size would be increased, operating cost would be reduced and the efficiency of management and decision-making would be improved as a benefit.

Massive funds need to be invested in tourism products innovation, which is unrealistic for smaller tourism enterprises. Tourism business has complicated and extensive industry chain facing all kinds of customers and suppliers, and it has to deal with more data than other businesses. Data sharing is very important in the tourism companies, small and medium tourism enterprises will be dependent on large-scale tourism enterprises, orbecome partners with other companies to manage the data otherwise it will be weed out this industry. The 15 markets in the first place were the United Kingdom, Taiwan, Russia, Japan, Hongkong, South Korea, Singapore, Australia, Germany, Thailand, the United States, Italy, France, Spain and Holland. According to the China Travel Depot to foreign tourists and leisure and airline ticket, hotel, tickets, etc. elements of booking data analysis, TOP10 of inbound tourism market, the United States, Germany, Britain, Australia and Japan, ranked in the top five, accounted for a relatively large; the remaining 6-10 were Spain, Canada, Italy, France and Malaysia. Of the network search, reservation is an important means of inbound tourists, short-range market does not show an absolute advantage, short-range, remote market overall in balanced development trend.

Although tourism enterprises have been aware of the importance of data, they still have not found a proper way to take advantage of data at present. With the development of economy and information technology, multinational companies have introduced shared services model to improve service quality and efficiency, promote the development of core business, accelerate the standardization process of the enterprise and reduce operational costs. Data-sharing model constructed in this paper is similar to shared service model in some way, but differences are apparent. Shared services model is only used within large enterprise, while data sharing for the tourism enterprises could be both internal and external. Data-sharing refers to the exchange of data among groups, divisions and organizations for the purpose of improving enterprises operating performance by the effective exchange, integration, and synergy of data. It can also be viewed as a combination of interaction, communication, and learning processes that allows enterprises to acquire information from others.

\section{CONCLUSION}

The comprehensive effect here from the perspective of factor endowment do comparative analysis is visible, the development of tourism industry in the angle of the influence from the economic performance of the tourism industry, in the early stage, the factor endowment of tourism resources as the representative of the impact on the economic performance of the tourism industry is more prominent. Compared with the actual situation of the development of the tourism industry in the central and western regions of China, it can be seen from the comparison of the regions in china. But as time goes on, the primary production factors in order to tourism resources as the representative of the impact on the tourism industry competitiveness and economic performance effect began to decrease, the actual situation of this point from the development of the tourism industry in eastern area of. Especially from the comparison of different factor endowment conditions on the economic performance of the tourism industry in the visible, labor, fixed assets investment and the impact of the role of human capital is more prominent, especially the elements of human capital. With the emphasis on the competition theory of Potter industry modernization of infrastructure, science and technology research and development, advanced professional talents with advanced production factors, the final decision will be the industry competitiveness and the level of economic performance significantly improved the most important source is basically the same. It can be said that with the passage of time, the economic performance of China's tourism industry to play a more important role in the development of tourism professionals, professionals and tourism related high-tech and other advanced, specialized tourism elements. Therefore, the establishment of advanced tourism elements of the development mechanism to promote the tourism industry to a higher stage of evolution, has become an important aspect of concern

\section{REFERENCES}

[1] Poon, A,Tourism technology and competitive strategies," 
Oxford:CAB International,1993.

[2] Sheldon, P, "Tourism information technologies," Oxford: CAB International ,1997.

[3] Dimitrios Buhalis, Rob Law,"Progress in information technology and tourism management: 20 years on and 10 years after the Internet-The state of eTourism research," Tourism Management. 29,2007,pp. 609-623.

[4] Dimitrios Buhalisa, Maria Cristina Licata,"The future eTourism intermediaries. ,"Tourism Management. 23,2002,pp. 207-220 .

[5] Samira Borouji Hojeghan, Alireza Nazari Esfangareh, "Digital economy and tourism impacts, influences and challenges. ,"Procedia
Social and Behavioral Sciences. 19, 2011,pp. 308-316.

[6] Ali Sukru Cetinkaya, "Information Communication Technologies in Tourism. ,"Tourism Management. 31,2010,pp. 150-151 .

[7] Unai Bastida ,T. C. Huan,"Performance evaluation of tourism websites' information quality of four global destination brands: Beijing, Hong Kong, Shanghai, and Taipei," Journal of Business Research,2012,pp. 1-4

[8] Xiaomei Shao, Qinglian Wang, "A research on the application of neural network technology in West Ocean tourism development," Geography and Territorial Research. 4,1998, pp. 55-59. ( In Chinese). 